\title{
ANALISIS PROTEKSI KEBAKARAN PADA PERUSAHAAN PRODUKSI GAS DAN PEMBANGKIT LISTRIK
}

\section{FIRE PROTECTION ANALYSIS ON GAS PRODUCTION COMPANY AND POWER PLANT}

\author{
Bery Romadhon \\ PT. PJB Service \\ E-mail: rbery13@gmail.com
}

\begin{abstract}
PT. Gresik Gases Indonesia and PT. Gresik Power Indonesia is a company engaged in the production of gas and power plants with natural gas and diesel power. This production site has a potential fire hazard so it must be implemented active and passive fire protection system. This research held to determine the suitability of active fire protection systems, passive in the workplace based on with several standards such as the SNI 03-3985-2000, NFPA 13, Permenaker no. 04/1980, Permen PU no. 26/PRT/M/2008, SNI 03-1745-2000. Observational data collection used regulated checklists, with cross-sectional research design. This production site was the potential for serious hazards to cause large area fire and in a short time. Classification of fire in this production of type A, B, C were derive from fuel oil storage tanks, T $80 C, T 80 \mathrm{D}, \mathrm{MCC} 20$ $K V$, SHEQ and admin office, ware house, gas compressor area, gas engines, combustion turbine, control room, centrifuge pump, and regent heater. Active fire protection was several assessments such as alarm, detector, sprinkler, exhaust, and hydrant. On passive fire protection, the assessment was based on buildings. Field observations obtained the following results active protection system such as alarm with enough categories, detector with enough categories, sprinkler with enough categories, a fire extinguisher with a good category, hydrants with good categories and on passive fire protection systems with sufficient category.
\end{abstract}

Keywords: fire protection, gas production, power plant

\begin{abstract}
ABSTRAK
PT. Gresik Gases Indonesia dan PT. Gresik Power Indonesia merupakan perusahaan yang bergerak di bidang produksi gas dan pembangkit listrik yang memiliki potensi bahaya kebakaran. Oleh karena itu, harus dilaksanakan sistem proteksi kebakaran. Penelitian ini dilaksanakan untuk mengetahui kesesuaian system proteksi kebakaran aktif dan pasif pada tempat kerja berdasarkan beberapa standar seperti SNI 03-3985-2000, NFPA 13, Permenaker no. 04/1980, Permen PU no. 26/ PRT/M/2008, dan SNI 03-1745-2000. Pengumpulan data secara observasional menggunakan checklist dengan rancangan penelitian cross-sectional. Tempat produksi ini memiliki potensi bahaya berat dapat menimbulkan kebakaran area besar dan dalam waktu singkat. Klasifikasi kebakaran di tempat produksi ini bertipe A, B, C yang berasal dari fuel oil storage tank, T $80 \mathrm{C}, \mathrm{T} 80 \mathrm{D}, \mathrm{MCC} 20 \mathrm{KV}$, SHEQ, kantor admin, ware house, gas compressor area, gas engine, combustion turbine, control room, centrifuge pump, dan regent heater. Proteksi kebakaran aktif memiliki beberapa penilaian seperti alarm, detektor, sprinkler, alat pemadam api ringan, serta hidran. Pada proteksi kebakaran pasif, penilaian berdasarkan pada bangunan gedung. Observasi di lapangan memperoleh hasil menunjukkan bahwa system proteksi aktif seperti alarm dalam kategori cukup, detector dalam kategori baik, sprinkler dalam kategori cukup, Alat Pemadam Api Ringan (APAR) dalam kategori baik, hidran dalam kategori baik, dan pada sistem proteksi kebakaran pasif dalam kategori cukup.
\end{abstract}

Kata kunci: pembangkit listrik, produksi gas, proteksi kebakaran

\section{PENDAHULUAN}

Perkembangan dunia menuntut perusahaan memberikan produk/jasa dengan jumlah besar dan kualitas baik. Listrik dan gas (oksigen, nitrogen, dan argon) merupakan kebutuhan manusia baik untuk industry maupun perorangan. Proses produksi gas dan pembangkit listrik mempunyai risiko kebakaran yang tinggi pada setiap proses produksi dan pembangkit listrik serta di tempat penyimpanan juga memiliki risiko kebakaran yang besar.

Keselamatan dan Kesehatan Kerja (K3) adalah setiap usaha yang dilaksanakan agar setiap pekerja atau semua orang yang berada di tempat kerja terlindungi dan tidak mendapat kecelakaan 
kerja serta meningkatkan efisiensi produksi dalam perusahaan. Keselamatan kerja adalah keselamatan yang berkaitan antara bahan baku pesawat kerja dan lingkungan kerja (Suma'mur, 2009).

Penggunaan teknologi dan bahan mudah terbakar yang digunakan, sudah seharusnya diiringi pula dengan peningkatan perlindungan terhadap pekerja yang sebagaimana telah diatur pada UU No. 1 Tahun 1970 tentang Keselamatan Kerja. Hal ini berarti mencakup jaminan keselamatan kerja dari bahaya kebakaran seperti yang tertuang pada pasal 3 ayat 1 dan pasal 9 ayat 3 yang berbunyi mencegah, mengurangi, dan memadamkan kebakaran.

Hingga beberapa tahun ini, bencana kebakaran sering terjadi baik di luar maupun di dalam negeri. Angka kejadian kebakaran di Amerika masih tinggi, yaitu sebesar 1.375.000 kasus kebakaran yang dilaporkan pada tahun 2012, mengakibatkan 2.855 penduduk meninggal, 16.500 cidera, dan kerugian properti kurang lebih sebesar \$12.400.00.00. Kejadian kebakaran di sektor nonresidential, pada tahun 2011 terjadi 85.400 kasus kebakaran dengan 80 korban jiwa, 1.100 cidera dan kerugian uang sebesar \$2.435.700.000 (National Fire Protection Association, 2013).

PT. PJB UP Brantas pernah terjadi kebakaran pada unit PLTU dan menimbulkan korban sebanyak 7 orang meninggal. Unit PLTA Sutami juga pernah terjadi kebakaran tetapi dalam skala kecil menyebabkan kebakaran akibat arus pendek turbin pada tahun 1996 (Kowara, 2016).

Kebakaran di bangunan bertingkat seperti gedung depan menyebabkan terjadinya korban jiwa dan korban materi dalam jumlah yang tidak sedikit. Tahun 2009 terjadi kebakaran di gedung PT. Kedaung Indah Can (KICI) Surabaya mengakibatkan kerugian mencapai Rp. 20 Miliar (Firdani, 2014).

Sistem manajemen kebakaran adalah upaya terpadu untuk mengelola risiko kebakaran mulai dari perencanaan, pelaksanaan, pemantauan, dan tindak lanjutnya. Ada berbagai elemen atau kegiatan kunci yang harus dijalankan dalam mengelola bahaya kebakaran (Ramli, 2010). Kegiatan pra kebakaran adalah langkah-langkah yang dilakukan sebelum kebakaran terjadi, atau disebut juga pencegahan kebakaran (fire prevention). Langkah ini seperti pemenuhan peralatan yang dibutuhkan sesuai standard yang ada sehingga dapat mencegah terjadinya pembesaran api. Kegiatan saat kebakaran (fire fighting) adalah langkah untuk menanggulangi dan memadamkan kebakaran secepat mungkin sehingga korban dan kerugian dapat dicegah. Selain langkah pemadaman ada juga langkah melakukan evakuasi kepada orang yang berada di tempat tersebut menuju ke tempat yang aman. Kegiatan pasca kebakaran adalah langkah yang dilakukan setelah kebakaran terjadi yaitu fase rehabilitasi dan rekonstruksi dampak kebakaran.

Item yang akan dinilai dalam penelitian ini adalah tahap persiapan sebelum terjadinya kebakaran. Tahap tersebut terdiri dari beberapa perlengkapan yaitu proteksi aktif dan pasif. Perlengkapan yang terdapat pada lapangan akan dibandingkan dengan beberapa standard yang berlaku yaitu SNI 03-39852000, NFPA 13, Permenaker No. 04/1980, Permen PU No. 26/PRT/M/2008, dan SNI 03-1745-2000.

Kebakaran merupakan reaksi antar komponen yang saling mendukung menyebabkan terjadinya api. Kebakaran tidak langsung terjadi dalam keadaan besar kebanyakan kebakaran diawali dari api kecil, kemudian membesar. Kebakaran yang terjadi dalam skala besar dan waktu singkat biasa berbahan bakar gas atau kebakaran jenis ledakan.

Seiring berkembangnya teknologi teori segitiga api berkembang dengan ditemukannya unsur ke empat terjadinya kebakaran yaitu rantai reaksi kimia (Chemical Chain Reaction). Teori ini disebut fire Tetrahedron, teori ini ditemukan berdasarkan penelitian bahan pemadam kebakaran tepung kimia (dry chemical) dan halon (halongeneted hydrocarbon) yang memiliki prinsip memecah ikatan kimia pada saat terjadinya kebakaran. Perlengkapan kebakaran juga berkembang sehingga memudahkan tim petugas kebakaran. Salah satu perkembangan yaitu nozzle memiliki 2 tipe yaitu jet (fix nozzle dan nozzle kombinasi). Jenis jet digunakan untuk semprotan jarak jauh, sedangkan kombinasi dapat diatur dengan bentuk pancaran lurus dan spray (Estria, 2008).

Setiap tempat kerja memiliki potensi kebakaran yang dapat terjadi. Setiap tempat kerja dapat digolongkan dalam klasifikasi kebakaran sesuai karakteristik bahan dan proses digunakan. Klasifikasi menurut Keputusan Menteri Tenaga Kerja Republik Indonesia No: Kep.186/MEN/1999 Tentang Unit Penanggulangan Kebakaran di Tempat Kerja, yaitu:

1. Klasifikasi tingkat potensi risiko kebakaran ringan

Tempat kerja yang mempunyai jumlah dan kemudahan terbakar rendah, saat terjadi kebakaran dapat melepaskan panas rendah, 
sehingga api menjalar dengan lambat. Biasanya terjadi pada tempat ibadah, gedung/ruang perkantoran, gedung/ ruang pendidikan, gedung/ ruang perumahan, gedung/ ruang perawatan, gedung/ ruang rumah sakit, dan lainnya.

2. Klasifikasi tingkat potensi risiko kebakaran sedang 1

Tempat kerja yang mempunyai jumlah dan kemudahan terbakar sedang, menimbun bahan dengan tinggi tidak lebih dari 2,5 meter dan apabila terjadi kebakaran dapat melepaskan panas sedang, sehingga menjalarnya api sedang. Contohnya tempat parkir, pabrik elektronika, pabrik susu, pabrik roti, pabrik barang gelas, dan lainnya.

3. Klasifikasi tingkat potensi risiko kebakaran sedang 2

Tempat kerja yang mempunyai jumlah dan kemudahan terbakar sedang, menimbun bahan dengan tinggi lebih dari 4 meter, dan apabila terjadi kebakaran melepaskan panas sedang, sehingga menjalarnya api sedang. Contohnya bengkel mesin, penggilingan padi, gudang pendinginan, pengolahan logam, perakitan kayu, pabrik tembakau, dan lainnya.

4. Klasifikasi tingkat potensi risiko kebakaran sedang 3

Tempat kerja yang mempunyai jumlah dan kemudahan terbakar tinggi, dan apabila terjadi kebakaran melepaskan panas tinggi, sehingga api cepat menjalar. Contoh tempat kerja: pabrik ban, pabrik karung, bengkel mobil, pabrik tembakau, pabrik lilin, pergudangan, pabrik pakaian, dan lainnya.

5. Klasifikasi tingkat potensi risiko kebakaran berat

Tempat kerja yang mempunyai jumlah dan kemudahan terbakar tinggi, menyimpan bahan cair, serat atau bahan lainnya dan apabila terjadi kebakaran apinya cepat membesar dengan melepaskan panas tinggi, sehingga menjalarnya api cepat. Contoh tempat kerja: pabrik kembang api, pabrik korek api, pabrik cat, pabrik bahan peledak, dan lainnya.

Sistem proteksi kebakaran atau sumber daya yang direncanakan untuk mencegah atau untuk penanggulangan pada kejadian kebakaran sesuai dengan tingkat risiko yang terdapat pada tempat kerja tertentu. Peraturan Kepmen PU Nomor 26/PRT/ M/2008 menyatakan bahwa setiap bangunan gedung harus mempunyai pengelolaan proteksi kebakaran untuk mencegah terjadinya penyebaran kebakaran ke ruangan ataupun ke bangunan lain. Sistem proteksi kebakaran terbagi 2 yaitu sistem proteksi aktif dan sistem proteksi pasif. Sistem proteksi kebakaran aktif adalah alat atau instalasi yang digunakan mendekteksi dan memadamkan kebakaran seperti sistem deteksi alarm, APAR, Hidran, dan Sprinkler dan Sistem proteksi kebakaran pasif adalah sistem yang digunakan untuk melindungi setiap orang yang berada di lokasi dengan pembuatan komponen konstruksi dan desain yang sedemikian rupa.

PT. Gresik Power Indonesia dan PT. Gresik Gases Indonesia merupakan perusahaan yang bergerak di bidang produksi listrik, gas oksigen, gas argon, dan gas nitrogen. Lingkungan kerja memiliki beberapa lokasi mudah terbakar dan sangat fatal apabila terjadi kebakaran. Lokasi tersebut tersebar di beberapa tempat seperti fuel oil storage tank, T-80C (oksigen strorage), natural gas comp stasion, gas engine 1-4, HRSG 1-3, centrifuge. Pelaksanaan sistem proteksi kebakaran harus dijalankan secara menyeluruh agar dapat mencegah terjadi kebakaran dan mengurangi kerugian apabila terjadi kebakaran (Romadhon, 2017).

\section{METODE}

Metode pengumpulan data yang digunakan pada penelitian ini bersifat observasional karena penelitian tidak memberikan intervensi terhadap sampel yang akan diteliti, tetapi secara langsung mengidentifikasi variabel yang diteliti dengan menggunakan pedoman peraturan yang menjadi patokan. Sedangkan, berdasarkan waktu penelitiannya bersifat crosssectional yaitu pengambilan data berdasarkan variabel yang diteliti secara bersamaan pada suatu saat tertentu.

Penelitian ini dilaksanakan di PT. Gresik Gases Indonesia dan PT. Gresik Power Indonesia. Lokasi tersebut dijadikan penelitian dikarenakan memiliki potensi kebakaran tinggi yang terdapat di beberapa tempat produksi. Waktu pengumpulan data pada 1-28 Februari 2017. Variabel dalam penelitian ini adalah pada aspek sistem proteksi kebakaran aktif dan pasif. Cara pengumpulan data diperoleh dengan menggunakan checklist yang berpedoman dengan SNI 03-3985-2000, NFPA 13, Permenaker No. 04/1980, Permen PU No. 26/PRT/M/2008, dan 
SNI 03-1745-2000. Peralatan proteksi kebakaran yang akan dinilai memiliki jumlah sesuai kebutuhan perusahaan antara lain 76 buah smoke detector, 26 buah heat detector, dan 91 Alat Pemadam Api Ringan (APAR). Penggolongan kesesuaian dapat dikategorikan $81-100 \%$ termasuk kategori baik. $60-80 \%$ kategori cukup dan $<60 \%$ dalam kategori jelek.

\section{HASIL}

Hasil penelitian yang diperoleh mengenai sistem proteksi kebakaran aktif dan pasif kebakaran yang dilakukan dengan observasi, pengukuran, dan telaah dokumen di PT. Gresik Gases Indonesia dan PT. Gresik Gases Indonesia (Linde) menjelaskan bahwa pabrik pembangkit tenaga listrik. Kontruksi Pabrik telah dimulai sejak Februari tahun 1997 ditandai dengan kegiatan penyiapan tanah hingga pembangunan dan selesai seluruhnya pada Oktober 1998. Produksi listrik pertama kali dicapai pada November tahun 1998 dan di supply ke PT. Smelting untuk membantu proses produksi pabrik peleburan dan pemurnian tembaga.

PT. Gresik Power Indonesia merupakan perusahaan pembangkit tenaga listrik dengan kapasitas energi listrik yang dihasilkan sebesar 43 MW melalui 4 unit Gas Engiene, 3 unit Combustion Turbin, dan 2 unit Steam Turbin untuk membangkitkan tenaga listrik serta 1 unit Steam Turbine lainnya di pasang pada air separation Unit (ASU). PT. Gresik Gases Indonesia memproduksi gas industri berupa nitrogen, argon, dan oksigen. Kapasitas produksi gas industri yang dihasilkan oleh PT. Gresik Gases Indonesia adalah Low Pressure Gas Oxygen $(\mathrm{LPGO})=29.280 \mathrm{Nm}^{3} / \mathrm{hr}$, High Presusure Gas Oxygen $(\mathrm{HPGO})=478 \mathrm{Nm}^{3} / \mathrm{hr}$, Gas Nitrogen $=5630 \mathrm{Nm}^{3} / \mathrm{hr}$, Liquid Oxygen $(\mathrm{LOX})=$ $70 \mathrm{TPD}$, Liquid Nitrogen $(\mathrm{LIN})=870 \mathrm{Nm}^{3} / \mathrm{hr}$, dan Liquid argon $\left(\right.$ Lar) $=384 \mathrm{Nm}^{3} / \mathrm{hr}$.

PT. Gresik Power Industri dan PT. Gresik Gases Indonesia mempunyai pembangkit dan fasilitasfasilitas pendukungnya. Pembangkit-pembangkit tersebut memanfaatkan teknologi modern berbasis komputer dengan menggunakan beragam energi primer seperti air, bahan bakar gas, bahan bakar solar, dan sebagainya.

\section{Identifikasi Bahaya}

Hasil observasi dan wawancara di PT. Gresik Power Indonesia dan PT. Gresik Gases Indonesia menunjukkan beberapa hal yang dapat menyebabkan

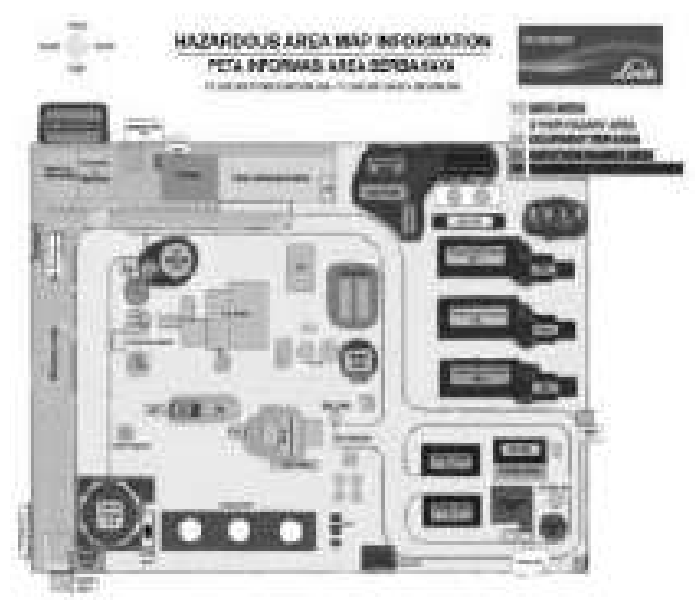

Gambar 1. Potensi Kebakaran.

kebakaran. Faktor penyebab kebakaran dapat dikelompokkan sesuai dengan teori segitiga api yang berasal dari udara (oksigen), panas, dan bahan-bahan mudah terbakar yang digunakan saat proses produksi berlangsung. Area dengan potensi kebakaran dapat dilihat dalam peta informasi area potensi kebakaran pada Gambar 1.

Sumber udara berasal dari oksigen yang terdapat pada udara sekitar lingkungan dan penyimpan liquid oksigen di PT. Gresik Power Indonesia dan PT Gresik Gases Indonesia. Sumber panas berasal dari mesin pembangkit listrik. Sumber bahan berasal dari bentuk padat (kertas, karet, kayu, karton, dan plastik); bentuk cair (solar); bentuk gas (LPG, gas oksigen, gas karbondioksida). Hasil identifikasi berdasarkan teori segitiga api di atas menunjukkan potensi bahaya kebakaran yang ada di PT. Gresik Power Indonesia dan PT. Gresik Gases Indonesia sudah cukup untuk memicu terjadinya kebakaran.

Klasifikasi tingkat potensi risiko kebakaran di PT. Gresik Power Indonesia dan PT. Gresik Gases Indonesia termasuk pada potensi bahaya tinggi berdasarkan Keputusan Menteri Tenaga Kerja Republik Indonesia No:Kep.186/MEN/1999 Tentang Unit Penanggulangan Kebakaran di Tempat Kerja. PT. Gresik Power Indonesia dan PT. Gresik Gases Indonesia memiliki potensi kebakaran tinggi. Jika terjadi kebakaran, apinya cepat membesar dengan melepaskan panas tinggi sehingga menjalarnya api cepat.

Hasil observasi di lapangan menunjukkan bahwa dari beberapa variabel sistem kebakaran aktif yang diteliti adalah alarm, detektor, APAR, dan hidran. Alarm dan detektor akan dibandingkan dengan SNI 03-3985-2000 tentang Tata Cara 
Tabel 1. Klasifikasi Kebakaran PT. Gresik Power Indonesia dan PT. Gresik Gases Indonesia Tahun 2017

\begin{tabular}{lll}
\hline \multicolumn{1}{c}{ Lokasi } & Potensi & Jenis \\
\hline fuel oil storage tank & - Solar & $\mathrm{B}$ \\
$-\mathrm{T} 80 \mathrm{C}$ & - Gas & $\mathrm{B}$ \\
$-\mathrm{T} 80 \mathrm{D}$ & & \\
MCC 20KV & - Listrik & $\mathrm{C}$ \\
SHEQ dan kantor & - Listrik & $\mathrm{A}$ \\
admin & - kertas & $\mathrm{C}$ \\
Ware house & - kertas & $\mathrm{A}$ \\
& - listrik & $\mathrm{C}$ \\
Office and & - Kertas & $\mathrm{A}$ \\
administration & - Listrik & $\mathrm{C}$ \\
building & & \\
Gas compressor & - gas & $\mathrm{B}$ \\
area & - minyak & \\
Gas engine & - Gas & $\mathrm{B}$ \\
Combustion turbine & - Solar & \\
Control room & - Solar & $\mathrm{B}$ \\
Centrifuge Pump & - Kertas & $\mathrm{C}$ \\
Regent heater & - Listrik & $\mathrm{B}$ \\
\hline
\end{tabular}

Perencanaan, Pengujian dan Pemasangan Sistem Deteksi dan Alarm Kebakaran. Kesesuaian APAR akan dibandingkan dengan Peraturan Menteri Tenaga Kerja No. 04/1980 dan Peraturan Menteri Pekerjaan Umum No.26/PRT/M/2008. Sedangkan hidran akan dibandingkan dengan SNI 03-1745-2000 tentang Tata Cara Perencanaan dan Pemasangan Sistem Pipa Tegak Dan Slang Untuk Pencegahan Bahaya Kebakaran.

Penilaian terhadap komponen alarm berupa terpasangnya alarm di tempat kerja, peletakan alarm yang mudah dilihat kemudian dijangkau serta suara alarm dapat terdengar ke seluruh tempat kerja, sinyal suara alarm berbeda dengan sinyal suara yang lain, alarm otomatis terhubung dengan sprinkler dan peletakan alarm pada jalur keluar dengan ketinggian 1,4 meter dari atas lantai.

Tabel 2, menunjukkan bahwa penilaian alarm di PT Gresik Power Indonesia dan PT. Gresik Gases Indonesia dengan mengunakan SNI 03-3985-2000 mendapatkan pemenuhan $80 \%$ artinya termasuk kategori cukup. Perlu dilakukan sedikit perbaikan terhadap komponen yang belum memenuhi.
Tabel 2. Hasil Observasi Alarm di PT. Gresik Power Indonesia dan PT. Gresik Gases Indonesia yang dibandingkan dengan SNI 03-39852000 Tahun 2017

\begin{tabular}{lcc}
\hline \multicolumn{1}{c}{ Lokasi } & Tingkat Pemenuhan & \% \\
\hline Seluruh tempat PT. & 4 dari 5 penilaian & $80 \%$ \\
Gresik Gases indonesia & & \\
dan PT. Gresik Power & & \\
Indonesia & & \\
\end{tabular}

Alarm yang terpasang di PT. Gresik Power Indonesia dan PT. Gresik Gases Indonesia yang telah memenuhi komponen penilaian yaitu terpasangnya alarm di tempat kerja, peletakan alarm yang mudah dilihat kemudian dijangkau serta suara alarm dapat terdengar ke seluruh tempat kerja, sinyal suara alarm berbeda dengan sinyal suara yang lain, dan peletakan alarm pada jalur keluar dengan ketinggian 1,4 meter dari atas lantai. Kemudian 1 komponen yang belum terpenuhi yaitu alarm otomatis terhubung dengan sprinkler.

PT. Gresik Power Indonesia dan PT. Gresik Gases Indonesia memiliki smoke detector sebanyak 76 buah dan heat detector sebanyak 20 buah yang tersebar di seluruh tempat indoor. Penilaian terhadap komponen detektor berupa penempatan sistem deteksi kebakaran pada titik-titik tertentu, penempatan detektor harus dapat dijangkau untuk dilaksanakan pemeliharaan berkala, terdapat perlindungan detektor untuk menghindari kerusakan akibat gangguan mekanis, jarak antar detektor maksimal 9,1 meter dan dilaksanakan inspeksi, pengujian serta pemeliharaan secara berkala kemudian melakukan pengarsipan.

Tabel 3, menunjukkan hasil penilaian menurut SNI 03-3985-2000, detektor kebakaran di PT. Gresik Power Indonesia dan PT. Gresik Gases Indonesia mendapatkan nilai skoring $100 \%$, sehingga tingkat pemenuhan adalah baik. Detektor yang terpasang di PT. Gresik Gases Indonesia dan PT. Gresik Power Indonesia telah memenuhi penilaian berupa penempatan sistem deteksi kebakaran pada titiktitik tertentu, penempatan detektor dapat dijangkau untuk dilaksanakan pemeliharaan berkala, terdapat pelindung detektor untuk menghindari kerusakan akibat gangguan mekanis, jarak antar detektor maksimal 9,1 meter dan dilaksanakan inspeksi, pengujian serta pemeliharaan secara berkala kemudian melakukan pengarsipan artinya telah memenuhi standard yang ada. 
Tabel 3. Hasil Observasi Detektor di PT. Gresik Power Indonesia dan PT. Gresik Gases Indonesia yang di bandingkan dengan SNI 03-3985-2000 Tahun 2017

\begin{tabular}{|c|c|c|}
\hline Lokasi & $\begin{array}{c}\text { Tingkat } \\
\text { Pemenuhan }\end{array}$ & $\%$ \\
\hline $\begin{array}{l}\text { Seluruh tempat } \\
\text { PT. Gresik } \\
\text { Gases indonesia } \\
\text { dan PT. Gresik } \\
\text { Power Indonesia }\end{array}$ & 5 dari 5 penilaian & $100 \%$ \\
\hline
\end{tabular}

Penilaian terhadap komponen sprinkler berupa terpasangnya sprinkler di tempat kerja, sprinkler tidak diberi warna serta ornamen atau lapisan tambahan, jaringan air untuk sprinkler bebas dari lumpur, sistem penyediaan air dikelola oleh perusahaan sendiri, terdapat sambungan yang digunakan untuk memompa air kedalam sprinkler, jarak antar sprinkler tidak lebih dari 4,6 meter, kepala sprinkler dalam keadaan baik dan tidak terhalang, memiliki cadangan kepala sprinkler $\leq 36$ buah, terhubung otomatis dengan alarm dan memiliki prosedur pemeriksaan serta uji coba.

Tabel 4, menunjukkan hasil penilaian sringkler menurut SNI 03-3989-2000 dan NFPA 13. Sprinkler di PT. Gresik Power Indonesia dan PT. Gresik Gases Indonesia mendapatkan nilai skoring $70 \%$. Sehingga tingkat pemenuhan adalah cukup artinya terpasang tetapi ada sebagian kecil yang tidak sesuai dengan standar yang berlaku.

Sprinkler yang terpasang di PT. Gresik Power Indonesia dan PT. Gresik Gases Indonesia telah memenuhi 7 komponen penilaian yaitu terpasangnya sprinkler di tempat kerja, sprinkler tidak diberi warna serta ornamen atau lapisan tambahan, jaringan air untuk sprinkler bebas dari lumpur, terdapat sambungan yang digunakan untuk memompa air

Tabel 4. Hasil Observasi Sprinklerdi PT. Gresik Power Indonesia dan PT. Gresik Gases Indonesia yang Dibandingkan dengan SNI 03-3989-2000 Tahun 2017

\begin{tabular}{|c|c|c|}
\hline Lokasi & $\begin{array}{c}\text { Tingkat } \\
\text { Pemenuhan }\end{array}$ & $\%$ \\
\hline $\begin{array}{l}\text { Seluruh tempat } \\
\text { PT. Gresik } \\
\text { Gases Indonesia } \\
\text { dan PT. Gresik } \\
\text { Power Indonesia }\end{array}$ & 7 dari 10 penilaian & $70 \%$ \\
\hline
\end{tabular}

kedalam sprinkler, jarak antar sprinkler tidak lebih dari 4,6 meter, kepala sprinkler dalam keadaan baik dan tidak terhalang, dan memiliki prosedur pemeriksaan serta uji coba. Komponen yang belum memenuhi adalah sistem penyediaan air dikelola oleh perusahaan sendiri, memiliki cadangan kepala sprinkler $\leq 36$ buah, dan terhubung otomatis dengan alarm.

PT. Gresik Power Indonesia dan PT. Gresik Gases Indonesia memiliki 91 titik peletakan APAR. Jenis APAR yang tersedia berjenis $\mathrm{CO}_{2}$, dry powder, AFF Foam, FE 36. Sesuai dengan jenis kebakaran yang terdapat pada tempat ini jenis kebakaran A, B, dan $\mathrm{C}$ penggolongan ini berdasarkan Permenaker no. 04/1980 dan Permen PU no. 26/PRT/M/2008.

Penilaian terhadap APAR berupa tersedianya alat pemadam api ringan (APAR), penempatan APAR sesuai dengan klasifikasi potensi kebakaran, APAR diletakkan pada tempat yang mudah dilihat, dicapai dan tidak terhalang, terpasang tanda peletakan APAR, APAR diletakkan menggantung atau di letakkan di lemari tidak terkunci, bagian atas APAR diletakkan $120 \mathrm{~cm}$ dari lantai, jarak antar APAR maksimal 15 meter, APAR diperiksa 2 kali dalam setahun, arsip seluruh APAR diperiksa dan disimpan, dan setiap APAR memiliki kartu kendali dengan menunjukkan bulan serta waktu pemeliharaan.

Tabel 5, menunjukkan penilaian terhadap APAR menurut Permenaker no. 04/1980 dan Permen PU no. 26/PRT/M/2008, APAR di PT. Gresik Power Indonesia dan PT. Gresik Gases Indonesia mendapatkan nilai skoring 96,7\%. Tingkat pemenuhannya tergolong baik artinya terpasang tetapi ada sebagian kecil yang tidak sesuai dengan standar yang berlaku.

APAR yang terpasang di PT. Gresik Power Indonesia dan PT. Gresik Gases Indonesia telah memenuhi penilaian berupa tersedianya alat

Tabel 5. Hasil Observasi APAR di PT. Gresik Gases Indonesia dan PT. Gresik Power Indonesia yang dibandingkan dengan Permenaker No. 04/1980 dan Permen PU no. 26/PRT/ M/2008 Tahun 2017

\begin{tabular}{llc}
\hline \multicolumn{1}{c}{ Lokasi } & Tingkat Pemenuhan & \% \\
\hline Seluruh tempat & 87 apar dari 91 & $96 \%$ \\
PT. Gresik & apar memenuhi 10 & \\
Gases Indonesia & penilaian & \\
dan PT. Gresik & & \\
Power Indonesia & & \\
\hline
\end{tabular}


Tabel 6. Hasil Observasi Hidrandi PT. Gresik Power Indonesia dan PT. Gresik Gases Indonesia yang dibandingkan dengan SNI 03-17452000 Tahun 2017

\begin{tabular}{lll}
\hline \multicolumn{1}{c}{ Lokasi } & \multicolumn{1}{c}{$\begin{array}{c}\text { Tingkat } \\
\text { Pemenuhan }\end{array}$} & \% \\
\hline Seluruh tempat & 10 dari 12 hidran & $83 \%$ \\
PT. Gresik Gases & memenuhi 10 & \\
Indonesia dan & penilaian & \\
PT. Gresik Power & & \\
Indonesia & & \\
\hline
\end{tabular}

pemadam api ringan (APAR), penempatan APAR sesuai dengan klasifikasi potensi kebakaran, APAR diletakkan pada tempat yang mudah dilihat, dicapai dan tidak terhalang, jarak antar APAR maksimal 15 meter, APAR diperiksakan 2 kali dalam setahun, arsip seluruh APAR diperiksa dan disimpan, dan setiap APAR memiliki kartu kendali dengan menunjukkan bulan serta waktu pemeliharaan. Penilaian APAR yang belum memenuhi secara keseluruhan berupa terpasang tanda peletakan APAR berjumlah 6 APAR $(6,6 \%)$, APAR diletakkan menggantung atau di letakkan di lemari tidak terkunci berjumlah $12(13,2 \%)$, bagian atas APAR diletakkan $120 \mathrm{~cm}$ dari lantai berjumlah $12(13,2 \%)$.

Penilaian terhadap hidran berupa tersedianya hidran yang cukup di lokasi pabrik, kotak hidran mudah dibuka kemudian mudah terlihat serta tidak terhalang benda apapun, peralatan di cat warna merah kemudian tulisan hidran berwarna merah, terdapat petunjuk penggunaan hidran, terdapat kelengkapan hidran (selang, kopling, nozzle, dan kran pembuka), terdapat hidran halaman, hidran terletak sepanjang jalur mobil pemadam kebakaran, jarak antar hidran kurang dari 50 meter, hidran halaman memiliki tekanan 3,5 bar dan dilakukan uji operasional setiap 1 tahun sekali.

Hidran yang terpasang di PT. Gresik Gases Indonesia dan PT. Gresik Power Indonesia telah memenuhi penilaian berupa tersedianya hidran yang cukup di lokasi pabrik, terdapat hidran halaman, jarak antar hidran kurang dari 50 meter, hidran halaman memiliki tekanan 3,5 bar dan dilakukan uji operasional setiap 1 tahun sekali. Hidran yang belum memenuhi kriteria penilaian secara keseluruhan berupa kotak hidran mudah dibuka kemudian mudah terlihat serta tidak terhalang benda apapun berjumlah 1 hidran $(8,4 \%)$, peralatan dicat warna merah kemudian tulisan hidran berwarna merah berjumlah 4 hidran (33\%), terdapat kelengkapan hidran (selang,
Tabel 7. Tingkat Pemenuhan Sistem Proteksi Kebakaran Aktif Tahun 2017

\begin{tabular}{lc}
\hline \multicolumn{1}{c}{ Komponen } & Persentase Pemenuhan \\
\hline Alarm & $80 \%$ \\
Detektor & $100 \%$ \\
Sprinkler & $70 \%$ \\
APAR & $96 \%$ \\
Hidran & $83 \%$ \\
\hline
\end{tabular}

kopling, nozzle dan kran pembuka) berjumlah 9 hidran (75\%), serta hidran terletak sepanjang jalur mobil pemadam kebakaran berjumlah 1 hidran $(8,4 \%)$.

PT. Gresik Power Indonesia dan PT. Gresik Gases Indonesia memiliki 12 buah hidran yang tersebar pada beberapa lokasi di seluruh perusahaan. Tabel 6 menunjukkan hasil penilaian kelengkapan hidran menurut SNI 03-1745-2000. Hidran di PT. Gresik Power Indonesia dan PT. Gresik Gases Indonesia mendapatkan nilai skoring 83\% sehingga tingkat pemenuhan adalah baik artinya terpasang sesuai dengan standar yang berlaku.

Tabel 7 menunjukkan tingkat pemenuhan sistem proteksi kebakaran di PT. Gresik Power Indonesia dan PT. Gresik Gases Indonesia. Komponen sistem proteksi kebakaran aktif yang masih perlu perhatian khusus untuk dilakukan upaya pengembangan ialah sprinkler dengan persentase pemenuhan standar sebesar $70 \%$.

Sistem proteksi kebakaran pasif di PT. Gresik Power Indonesia dan PT. Gresik Gases Indonesia dianalisis menggunakan lembar observasi dan dibandingkan dengan Permen PU No.26/PRT/ M/2008 tentang Persyaratan Teknis Sistem Proteksi Kebakaran pada Bangunan Gedung dan Lingkungan dan SNI 03-1736-2000. Hasil observasi sistem proteksi kebakaran pasif di PT. Gresik Power Indonesia dan PT. Gresik Gases Indonesia dapat dilihat dalam Tabel 8.

Penilaian terhadap sistem proteksi kebakaran pasif berupa adanya dinding penghalang api, adanya pintu tahan api, pemeliharaan berkala terhadap konstruksi tahan api, pintu tahan api dapat menutup secara otomatis, dan terdapat jendela tahan api.

Sistem proteksi kebakaran pasif yang terdapat di PT. Gresik Power Indonesia dan PT. Gresik Gases Indonesia telah memenuhi penilaian berupa terdapat dinding penghalang api, terdapat pintu tahan api, pintu tahan api dapat menutup secara otomatis dan terdapat jendela tahan api. Komponen sistem 
Tabel 8. Hasil Observasi Sistem Proteksi kebakaran Pasif Tahun 2017

\begin{tabular}{lcc}
\hline \multicolumn{1}{c}{ Lokasi } & \multicolumn{1}{c}{$\begin{array}{c}\text { Tingkat } \\
\text { Pemenuhan }\end{array}$} & $\%$ \\
\hline Seluruh tempat & 4 dari 5 penilaian & $80 \%$ \\
PT. Gresik Gases & & \\
Indonesia dan & & \\
PT. Gresik Power & & \\
Indonesia & & \\
\hline
\end{tabular}

proteksi kebakaran yang belum memenuhi penilaian berupa pemeliharaan berkala terhadap konstruksi tahan api.

Tabel 8 menunjukkan bahwa penilaian sistem proteksi kebakaran pasif di PT. Gresik Power Indonesia dan PT. Gresik Gases Indonesia menurut Permen PU No. 26/PRT/M/2008 mendapatkan nilai $80 \%$. Tingkat pemenuhan adalah cukup artinya terpasang tetapi ada sebagian kecil yang tidak sesuai dengan standar yang berlaku.

\section{PEMBAHASAN}

\section{Identifikasi Kebakaran}

Hasil klasifikasi kebakaran pada PT. Gresik Power Indonesia dan PT. Gresik Gases Indonesia secara umum terdapat 3 jenis sumber daya yang dapat menyebabkan kebakaran di PT. Gresik Power Indonesia dan PT. Gresik Gases Indonesia. Di PT. Gresik Power Indonesia dan PT. Gresik Gases Indonesia terdapat bahan-bahan mudah terbakar yang di gunakan selama proses kegiatan produksi bahan padat (kertas, karton, plastik), bahan cair (solar dan bensin), serta gas (gas oksigen, gas alam) yang dapat bereaksi dengan sumber panas seperti nyala api, energi listrik, temperatur tinggi, dan udara yang mengandung oksigen dapat menghasilkan api sehingga dapat terjadi kebakaran.

Teori segitiga api menyebutkan bahwa api dapat muncul apabila 3 unsur terdapat pada suatu tempat dan saling bereaksi. Unsur tersebut terdiri dari bahan bakar, oksigen, dan panas. PT. Gresik Power Indonesia dan PT. Gresik Gases Indonesia dalam proses produksinya terdapat 3 unsur tersebut, sehingga akan sangat rawan terjadi kebakaran. Suma'mur (1989) menyebutkan bahwa pengelompokan ketiga unsur tersebut adalah bahan mudah terbakar, panas, dan oksigen.

\section{Klasifikasi Bahaya Kebakaran}

Bangunan PT. Gresik Power Indonesia dan PT. Gresik Gases Indonesia termasuk dalam klasifikasi tingkat risiko bahaya berat karena apabila terjadi kebakaran pada tempat produksi akan menghasilkan ledakan atau menjalar dengan cepat dan melepaskan api dengan suhu tinggi.

Hasil identifikasi potensi bahaya kebakaran yang terdapat di PT. Gresik Power Indonesia dan PT. Gresik Gases Indonesia terdapat 3 jenis kelas kebakaran, yaitu golongan A (kebakaran akibat bahan padat selain logam), golongan B (kebakaran yang diakibatkan bahan bakar jenis cair dan gas), serta golongan jenis $\mathrm{C}$ (kebakaran pada listrik tegangan tinggi). Hal tersebut sesuai dengan Peraturan Menteri Tenaga Kerja dan Transmigrasi No: Per.04/MEN/1980. Hasil observasi dan telaah dokumen kemudian dilakukan analisis perbandingan sistem proteksi kebakaran aktif dan pasif pada PT. Gresik Power Indonesia dan PT. Gresik Gases Indonesia dengan SNI 03-3985-2000, NFPA 13, Permenaker No. 04/1980, Permen PU No. 26/PRT/ M/2008, serta SNI 03-1745-2000.

\section{Analisis Proteksi Kebakaran Aktif}

\section{Analisis Pemasangan Alarm}

Hasil perbandingan penerapan dan penyediaan alarm di PT. Gresik Gases Indonesia dan PT. Gresik Power Indonesia dengan SNI 03-39852000 terdapat unsur yang belum terpenuhi yaitu belum tersambungnya alarm secara otomatis dengan sprinkler, tetapi alarm kebakaran langsung tersambung dengan ruang kontrol pusat sehingga jika terjadi kebakaran dapat dilaporkan segera dan ditangani secara manual. Cara seperti ini kurang efektif apabila asal kebakaran di tempat kerja jarang di lalui pekerja atau terletak di ketinggian.

\section{Analisis Pemasangan Detektor}

Hasil perbandingan penerapan dan penyediaan detektor di PT. Gresik Gases Indonesia dan PT. Gresik Power Indonesia dengan SNI 03-39852000 menunjukkan bahwa telah memenuhi seluruh unsur. Detektor yang terdapat di PT. Gresik Gases Indonesia dan PT. Gresik Power Indonesia telah memenuhi semua aspek penilaian dari segi peletakan, perawatan tidak ada penghalang, mekanis, inspeksi rutin juga telah dilakukan oleh perusahaan. 


\section{Analisis Pemasangan Sprinkler}

Hasil perbandingan penerapan dan penyediaan sprinkler di PT. Gresik Gases Indonesia dan PT. Gresik Power Indonesia dengan SNI 03-39892000 menunjukkan bahwa beberapa unsur belum memenuhi standar, seperti tidak memiliki cadangan dan kepemilikan pompa sendiri untuk akses air, tidak adanya cadangan kepala sprinkler minimal 36 kepala sprinkler di perusahaan. Cadangan kepala sprinkler diperlukan untuk penggantian sewaktu-waktu setelah kepala sprinkler rusak. Kekurangan cadangan kepala sprinkler mengakibatkan penggantian terhadap kepala sprinkler akan terhambat sehingga dapat berpotensi fungsi sprinkler tidak sempurna.

Kepemilikan pompa air untuk akses sprinkler merupakan syarat yang harus dipenuhi. Perusahaan PT. Gresik Gases Indonesia dan PT. Gresik Power Indonesia tidak memiliki pompa sendiri yang didirikan di wilayah pabrik. Perusahaan ini menggunakan sistem pompa bersama dengan perusahaan mitra dengan pompa yang memiliki tekanan 8 bar. Pompa berfungsi untuk men-supply air ke seluruh lokasi sehingga apabila tidak memiliki rumah pompa sendiri akan sulit untuk melakukan pengecekan terhadap kondisi pompa.

\section{Analisis Pemasangan APAR}

PT. Gresik Power Indonesia dan PT. Gresik Gases Indonesia menggunakan beberapa jenis alat pemadam api ringan seperti dry powder, $\mathrm{CO}_{2}$, foam, FE36 yang diletakkan di seluruh tempat kerja. Hasil perbandingan APAR di PT. Gresik Gases Indonesia dan PT. Gresik Power Indonesia dengan Permenaker No. 04/1980 dan Permen PU No. 26/PRT/M/2008 menunjukkan terdapat beberapa APAR belum memenuhi unsur.

Unsur yang belum terpenuhi, seperti peletakan kurang dari $120 \mathrm{~cm}$, peletakan APAR di lantai sehingga pada saat pengambilan APAR dalam keadaan darurat akan sedikit menghambat. Tanda petunjuk penempatan APAR pada beberapa titik mengalami kerusakan dapat mengakibatkan bertambahnya waktu pencarian oleh pekerjaan pada saat terjadi kebakaan. Unsur pada penilaian alat pemadam api ringan yang telah terpenuhi seperti penempatan apar tidak terhalang oleh benda, penempatan dalam lemari tidak dalam kondisi terkunci, jarak setiap alat pemadam api ringan tidak lebih dari 15 meter dan kartu kendali pemeriksaan alat pemadam api ringan pada tabung atau lemari penyimpanan.

\section{Analisis Pemasangan Hidran}

Hasil perbandingan hidran ada di PT. Gresik Gases Indonesia dan PT. Gresik Power Indonesia dengan SNI 03-1745-2000 menunjukkan terdapat beberapa hidran yang tidak memenuhi unsur yaitu sebanyak 9 hidran tidak memiliki perlengkapan pemadam, tidak ada petunjuk penggunaan hidran, serta 4 kotak tidak memiliki kotak hidran. Kerusakan pada kotak hidran banyak terjadi pada cooling tower yang menggunakan air asin untuk mendinginkan mesin air yang tersiram di area cooling tower tersebut mengakibatkan korosi pada besi kotak hidran. Selain pada cooling tower, area penyimpanan gas juga banyak terjadi kerusakan karena besi kotak hidran menerima suhu sangat rendah hingga di bawah nol sehingga mempercepat kerusakan pada perlengkapan hidran.

Petunjuk penggunaan hidran juga tidak tertera pada seluruh kotak hidran sehingga akan menyulitkan bagi pekerja yang akan mengoperasikan hidran tersebut. Kelengkapan untuk kotak hidran seperti selang, kopling, nozzle, dan keran pembuka pada 9 dari 12 hidran belum terpenuhi pada saat pemakaian darurat akan menghambat proses pemadaman api pada perusahaan.

\section{Analisis Proteksi Kebakaran Pasif}

Hasil perbandingan sistem proteksi kebakaran pasif di PT. Gresik Gases Indonesia dan PT. Gresik Power Indonesia dengan Permen PU no.26/PRT/ $\mathrm{M} / 2008$ dan SNI 03-1736-2000 menunjukkan terdapat unsur yang belum memenuhi yaitu perawatan berkala terhadap bangunan tahan api. Unsur penilaian yang telah terpenuhi seperti terdapat pintu tahan apa di setiap ruang kantor di lokasi perusahaan. Pintu tahan api dapat menutup secara otomatis dan memiliki kaca jendela yang tahan api.

\section{SIMPULAN}

Potensi risiko kebakaran yang ada di PT. Gresik Power Indonesia dan PT. Gresik Gases Indonesia berdasarkan tabel AS/NZS 4360:2004 termasuk dalam kategori $\mathrm{V}$ untuk severity dan $\mathrm{D}$ untuk likehood. Berdasarkan sumber bahayanya, beberapa hal yang dapat menyebabkan terjadi kebakaran antara lain sumber udara yaitu oksigen dan penyimpan liquid oksigen; sumber panas yaitu gas engiene, combustion turbine, steam turbine; dan sumber bahan seperti kertas, solar, gas alam, dan 
lain-lain yang dapat diklasifikasikan dalam kelas kebakaran A, B, dan C.

Sistem proteksi kebakaran aktif di PT. Gresik Power Indonesia dan PT. Gresik Gases Indonesia mendapatkan hasil alarm dengan kategori cukup, detektor dengan kategori baik, sprinkler dengan kategori cukup, alat pemadam api ringan dengan kategori baik dan hidran dengan kategori baik. Sistem proteksi kebakaran pasif di PT. Gresik Power Indonesia dan PT. Gresik Gases Indonesia termasuk dalam kategori cukup.

\section{DAFTAR PUSTAKA}

Estria, C., 2008. Evaluasi Sistem Penanggulangan Kebakaran di Kapal Penumpang KM. Lambelu PT. Pelayaran Nasional Indonesia (PT. PELNI) Tahun 2008. Skripsi. Depok Universitas Indonesia.

Firdani, L., 2014. Analisis Penerapan Alat Pemadam Api Ringan (APAR) Di PT. X Pekalongan. Jurnal. Semarang: Fakultas Kesehatan Masyarakat Universitas Diponegoro.

Keputusan Menteri Pekerjaan Umum No. 10/ KPTS/2000 Ketentuan Teknis Pengamanan Terhadap Bahaya Gedung dan Lingkungan. Jakarta: Departemen Pekerjaan Umum RI.

Kowara, R.A., 2016. Analisis Sistem Proteksi Kebakaran Sebagai Upaya Pencegahan dan Penanggulangan Kebakaran di PT. PJB Up Brantas Malang. Skripsi. Surabaya: Universitas Airlangga.

National Fire Proctetion Association., 2012. NFPA 13 Installation of Sprinkler Systems. USA: NFPA.

National Fire Protection Association., 2013. Fire loss in the United States. [Online] Tersedia di: $<$ www.nfpa. org/research/reports-and-statistics/ fires-in-the-us/overall-fire-problem/fire-loss-inthe-united-states $>$ [Diakses 27 April 2017].

Peraturan Menteri Pekerjaan Umum Nomor 26/ PRT/M/2008 Tentang Persyaratan Teknis Sistem Proteksi Kebakaran Pada Bangunan Gedung dan Lingkungan. Jakarta: Badan Penerbit PU.
Peraturan Menteri Tenaga Kerja dan Transmigrasi No. Per 04/MEN/1980 Tentang Syarat-Syarat Pemasangan dan Pemeliharaan APAR. Jakarta: Kementerian Tenaga Kerja dan Transmigrasi RI.

Peraturan Menteri Tenaga Kerja dan Transmigrasi No. Kep 186/MEN/1999 tentang Penanggulangan Kebakaran di Tempat Kerja. Jakarta: Kementerian Tenaga Kerja dan Transmigrasi RI.

Ramli, S., 2010. Seri Manajemen K3: Pedoman Praktis Manajemen Kebakaran. 3-4 ed. Jakarta: Dian Rakyat.

Romadhon, B., 2017. Analisis Sistem Proteksi Kebakaran dan Safety Sign di PT. Gresik Power Indonesia dan PT. Gresik Gases Indonesia. Laporan Magang. Surabaya: Universitas Airlangga.

Suma'mur., 1989. Keselamatan Kerja dan Pencegahan Kecelakaan. Jakarta: CV Haji Masagung.

Suma'mur, P. K., 2009. Higiene Perusahaan dan Kesehatan Kerja. Cetakan XII. Jakarta: PT. Toko Gunung Agung.

SNI 03-1736-2000 Tata Cara Perencanaan Sistem Proteksi Pasif untuk Pencegahan Bahaya Kebakaran pada Bangunan Rumah dan Gedung. Jakarta: Badan Standar Nasional Indonesia.

SNI 03-1745-2000 Tata Cara Perencanaan dan Pemasangan Sistem Pipa Tegak dan Slang untuk Pencegahan Bahaya Kebakaran. Jakarta: Badan Standar Nasional Indonesia.

SNI 03-3985-2000 Tata Cara Perencanaan, Pengujian dan Pemasangan Sistem Deteksi dan Alarm Kebakaran. Jakarta: Badan Standar Nasional Indonesia.

SNI 03-3989-2000 Tata Cara Perencanaan dan Pemasangan Sistem Sprinkler Otomatik untuk Pencegahan Bahaya Kebakaran pada Bangunan Gedung. Jakarta: Badan Standar Nasional Indonesia.

Undang-Undang No. 1 Tahun 1970 Tentang Keselamatan Kerja. Jakarta: Ditjen Pembinaan Pengawasan Ketenagakerjaan. 